\title{
Interleukin-6 and interleukin-8 blood levels' poor association with the severity and clinical profile of ex-smokers with COPD
}

This article was published in the following Dove Press journal:

International Journal of COPD

29 July 2014

Number of times this article has been viewed

Maria Rosedália de Moraes' Adeliane Castro da Costa ${ }^{2}$ Krislainy de Sousa Corrêa ${ }^{2}$ Ana Paula Junqueira-Kipnis ${ }^{2}$ Marcelo Fouad Rabahi ${ }^{3}$

'Health Sciences of Federal University of Goiás, Institute of Tropical Pathology and Public Health, Federal University of Goiás, Goiânia, Goiás, Brazil; ${ }^{3}$ Faculty of Medicine, Federal University of Goiás, Goiânia, Goiás, Brazil
Correspondence: Marcelo Fouad Rabahi Universidade Federal de Goiás Avenida B número 483, Setor Oeste, Goiânia, Goiás CEP 74I I0-030, Brazil Email mfrabahi@gmail.com
Background: The role of interleukins in the severity and clinical profile of chronic obstructive pulmonary disease (COPD) is not known, but evidence supports the contribution of systemic inflammation to disease pathophysiology. This study evaluated the relationship of serum biomarkers to the severity and clinical parameters of COPD.

Methods and findings: Serum levels of high-sensitivity C-reactive protein, interleukin-6 (IL-6), and interleukin-8 (IL-8) were measured in 50 patients with stable COPD and in 16 controls. The levels of these biomarkers were compared with parameters of severity, such as the grading of flow obstruction using the recommendations of the Global initiative for chronic Obstructive Lung Disease, the BMI (body mass index), obstruction, dyspnea, exercise capacity (health index) index, the number of exacerbations within the last year, and peripheral oxygen saturation after the six-minute walk test, and with clinical parameters, such as bronchitis and non-bronchitis phenotypes, the number of associated comorbidities, and the smoking burden. COPD patients exhibited higher levels of IL-6 and IL-8 compared to the control group. Higher levels of IL-6 occurred in COPD groups with body mass index $<21 \mathrm{~kg} / \mathrm{m}^{2}$, with more than two exacerbations in the past year, with a higher smoking burden, and with bronchitis. The increase in serum IL- 8 was found only in the group with the highest number of exacerbations within the previous year.

Conclusion: Increased IL-6 was mainly associated with smoking burden, in patients who had smoked for more than 30 pack-years and exhibited a bronchitis phenotype. No direct association was observed for both IL-6 and IL-8 blood levels with the severity of COPD in ex-smokers.

Keywords: COPD, interleukin-6, interleukin-8, C-reactive protein

\section{Introduction}

Chronic obstructive pulmonary disease (COPD) is the fifth leading cause of mortality worldwide, and it is responsible for $5.1 \%$ of deaths. ${ }^{1}$ This disease is characterized by a chronic and progressive airway obstruction that is associated with an increased inflammatory response to noxious particles. Tobacco is the primary causal agent of COPD, but genetic factors, chronic infections, and other environmental exposures, such as wood smoke, are also associated with COPD. ${ }^{2,3}$

The inhalation of tobacco and toxic gases initiates the pulmonary inflammatory cascade, which includes many cell types and inflammatory mediators that produce tissue injury without effective repair and changes in the structure of the airways. ${ }^{4-6}$ High levels of circulating polymorphonuclear leukocytes and an increase in inflammatory markers, including $\mathrm{C}$-reactive protein (CRP), fibrinogen, tumor necrosis factor alpha, and interleukins (IL), such as IL-8, IL-6, IL-1 $\beta$, IL-10, and IL-12, participate in this process, which persists despite smoking cessation. ${ }^{7}$ 
Elevated levels of CRP, IL-6, and IL-8 are associated with diminished forced expiratory volume in 1 second $\left(\mathrm{FEV}_{1}\right)$, and increased dyspnea and grading as Global initiative for chronic Obstructive Lung Disease (GOLD) stages 3 and 4 in COPD patients, ${ }^{8,9}$ which supports the relationship of these inflammatory mediators with COPD severity. ${ }^{10-12}$ The inverse relationship of CRP and IL-6 to $\mathrm{FEV}_{1}$ supports a function of these proteins in the obstructive process of COPD. ${ }^{9}$ These results support the importance of these biomarkers as new mechanisms for the identification of COPD severity.

Recent research has focused on phenotypes to determine new approaches in COPD patients. ${ }^{13,14}$ These studies evaluated biomarker levels with clinical-functional approaches and prognosis to broaden the evaluation of COPD severity; current smokers were excluded because cigarette smoke induces systemic inflammation. ${ }^{15,16}$ Nowadays, little data are available regarding the impact of smoking cessation on chronic inflammation, both in the lungs and system-wide. ${ }^{17}$ Therefore, the present study provides value by assessing the inflammatory status of different clinical profiles in a population composed only of former smokers.

The aim of this study was to understand if the severity of the clinical status of COPD patients who were ex-smokers was associated with inflammatory markers such as IL-6 and IL-8.

\section{Methods}

\section{Study population}

This study was a cross-sectional analytical study using nonprobability convenience sampling. This study included 50 COPD patients in the stable phase who were ex-smokers aged $\geq 40$ years; presented with $\mathrm{FEV}_{1}$ /forced vital capacity $(\mathrm{FVC})<0.7$, measured 15 minutes after the administration of $400 \mu \mathrm{g}$ of inhaled salbutamol (Aerolin ${ }^{\circledR}$; GlaxoSmithKline plc, London, UK); and had a smoking history of $\geq 10$ packyears. Sixteen control subjects aged $\geq 40$ years with normal lung function $\left(\mathrm{FEV}_{1} / \mathrm{FVC}>0.7\right)$ and no history of smoking were also included. Individuals using systemic corticoids, statin therapy, immunosuppressant drugs, and/or antibiotic therapy 30 days prior to inclusion were excluded from the study. Subjects reported no previous history of asthma, chronic systemic inflammatory disease, congestive cardiac failure, or severe coronary artery disease. Individuals with grade III obesity (body mass index [BMI] $\geq 40 \mathrm{~kg} / \mathrm{m}^{2}$ ) and pregnant and nursing women were also excluded.

The patients were categorized by stage of airflow obstruction using the GOLD 2011 criteria $^{18}$ and BMI (body mass index), obstruction, dyspnea, exercise capacity (health index; BODE) index, which includes the 6-minute walk test (6MWT), the dyspnea index of the Modified Medical Research Council (mMRC), BMI, and $\mathrm{FEV}_{1}$. Patients were also categorized by the number of exacerbations per year and peripheral oxygen saturation $\left(\mathrm{SpO}_{2}\right)$ after the 6MWT. The bronchitis and non-bronchitis phenotypes, number of associated comorbidities, and smoking burden were used for the clinical evaluation. The classification of patients with the bronchitis phenotype used the following criteria: presence of productive cough for more than 3 months in two successive years. ${ }^{19}$ All patients who did not meet these criteria were classified as non-bronchitis. We chose this classification because the definition of emphysema is not clinical ("increase of air spaces distal to the terminal bronchioles, with destruction of the walls") ${ }^{19}$ and brings serious operational problems. ${ }^{20}$

COPD patients were also classified according to medication: patients who used inhaled corticoid-based medication (group 2) and patients who did not use inhaled corticoids (group 1). The individuals underwent blood sample collection, pulmonary function tests, and 6MWT with $\mathrm{SpO}_{2}$ monitoring.

The Committee on Research Ethics of the General Hospital of the Federal University of Goiás approved this study, which followed the regulations for human research established by the Brazilian National Health Council (CNS) Resolution CNS 196/96 and was conducted in accordance with the principles expressed in the Declaration of Helsinki. All of the individuals freely signed an informed consent form.

\section{Pulmonary function tests}

All subjects underwent pulmonary function testing using the spirometer EasyOne ${ }^{\circledR}$ (Fleximed, ndd Medizintechnik AG, Zürich, Switzerland). The methods and criteria used were those recommended by the American Thoracic Society. ${ }^{21}$ First, the patients were weighed and measured. Spirometry measurements were obtained before and 15 minutes after inhalation of bronchodilator salbutamol $(400 \mu \mathrm{g})$. $\mathrm{FEV}_{1}$ was evaluated and $\mathrm{FEV}_{1}$ percentage predicted $\left(\mathrm{FEV}_{1} \%\right)$ and $\mathrm{FVC}$ were assessed after the use of a bronchodilator. The predicted values were established according to the methods of Pereira et al. ${ }^{22}$

\section{MWT}

The 6MWT was performed according to the regulations of the American Thoracic Society. ${ }^{23}$ The following parameters were used for statistical analyses: distance achieved and $\mathrm{SpO}_{2}$ after the 6MWT.

\section{Peripheral blood measurements}

Plasma levels of IL-6 and IL-8 were measured using an enzyme-linked immunosorbent assay and the BD OptEIA ${ }^{\mathrm{TM}}$ 
kit (BD Biosciences, San Jose, CA, USA) according to the manufacturer's instructions. The detection limits were $4.7 \mathrm{pg} / \mathrm{mL}$ and $3.1 \mathrm{pg} / \mathrm{mL}$, respectively.

Highly sensitive CRP (hs-CRP) was quantified in serum samples using chemiluminescence and Immullite ${ }^{\circledR}$ 2000 equipment (Siemens AG, Erlangen, Germany). The detection limits were $0.2-100 \mathrm{mg} / \mathrm{L}$.

\section{Statistical analysis}

Optical density dose conversion in picograms per milliliter was performed using linear regression analysis from the standard curve of each test. The results obtained were entered into Microsoft Excel 2010 (Microsoft Corporation, Redmond, WA, USA). All statistical analyses were performed in GraphPad Prism 5.0 (GraphPad Software, Inc., La Jolla, CA, USA). The nonparametric data are reported as mean \pm standard deviation. Across-group comparison of tree groups was done by the nonparametric Kruskal-Wallis test followed by Dunn's post hoc test. Direct comparisons between two groups were performed with the nonparametric Mann-Whitney test. Fisher's exact test evaluated the differences between the percentages of comorbidities and the difference between sexes. The chi-square test evaluated the differences between the percentages of comorbidities. Differences were considered significant when $P<0.05$.

\section{Results \\ Clinical characteristics of the study population}

The clinical characteristics of the study population are presented in Table 1.

The ages of COPD patients and controls were comparable with a mean and standard deviation of $63.7 \pm 7.8$ years in the control group and 66.6 \pm 8.9 years in the study group $(P=0.2709)$. The proportion between sexes was also comparable $(P=0.417)$ (Table 1$)$.

The frequency of comorbidities with confounding factors that could interfere with the blood levels of the studied biomarkers was evaluated in each group. The COPD group exhibited an incidence of arterial hypertension of $36.4 \%$ compared to $63.6 \%$ in the control group, and this difference between groups was significant $(P=0.04)$. The groups exhibited similar incidences of the other comorbidities with no significant differences. The most common comorbidities in this study were osteoporosis, diabetes, dyslipidemia, osteoarthrosis, arrhythmia, gastritis, depression, peripheral vasculopathy, and cardiovascular disease.

\section{Comparison of inflammatory serum biomarker levels in COPD patients and the control group}

The patients were divided according to the use of inhaled corticoid treatment as a confounding factor for the evaluation of biomarkers. COPD patients who were using inhaled corticoids revealed higher levels of IL-6 $(28.70 \pm 29.96 \mathrm{pg} / \mathrm{mL})$ than the control group $(5.42 \pm 3.72 \mathrm{pg} / \mathrm{mL} ; P=0.0156)$. In contrast, no difference was observed between the two COPD groups. IL-8 levels were higher in COPD patients who were not using inhaled corticoids $(22.47 \pm 11.79 \mathrm{pg} / \mathrm{mL})$ than in the control group $(13.05 \pm 6.73 \mathrm{pg} / \mathrm{mL} ; P=0.0154)$. Again no difference was found when COPD patients were using or not using inhaled corticoids. The levels of hs-CRP did not increase significantly.

In general, COPD patients exhibited higher serum levels of IL-6 (28.20 $\pm 29.86 \mathrm{pg} / \mathrm{mL})$ and IL-8 $(21.01 \pm 13.63 \mathrm{pg} / \mathrm{mL})$

Table I Demographics and clinical characteristics of COPD patients according to GOLD grading, from November 2010 to October 2011

\begin{tabular}{|c|c|c|c|c|c|}
\hline & $\begin{array}{l}\text { GOLD I-II } \\
n=\mid 4(\text { mean } \pm \text { SD })\end{array}$ & $\begin{array}{l}\text { GOLD III-IV } \\
n=36(\text { mean } \pm \text { SD })\end{array}$ & $\begin{array}{l}\text { COPD patients } \\
n=50(\text { mean } \pm S D)\end{array}$ & $\begin{array}{l}\text { Control } \\
n=16(\text { mean } \pm S D)\end{array}$ & $P$-value \\
\hline Age (mean \pm SD) & $62.9 \pm 9.0(44-76)$ & $67.8 \pm 8.8(50-85)$ & $66.6 \pm 8.9(44-85)$ & $63.7 \pm 7.8(68-76)$ & 0.2709 \\
\hline Male n (\%) & $6(42.8)$ & $8(2 I)$ & $36(72)$ & $9(56.3)$ & 0.417 \\
\hline $\mathrm{BMI}($ mean $\pm \mathrm{SD})$ & $25.9 \pm 5.1$ & $22.5 \pm 3.6$ & $23.3 \pm 4.4$ & $26.5 \pm 4.7$ & $0.0324 *$ \\
\hline $\mathrm{FEV}_{1} / \mathrm{FVC}(\%)($ mean $\pm \mathrm{SD})$ & $64.1 \pm 0.08$ & $33.2 \pm 0.07$ & $41.8 \pm 0.16$ & $80.4 \pm 0.03$ & $<0.000 I^{*}$ \\
\hline $\mathrm{FEV}_{1}(\%)($ mean $\pm \mathrm{SD})$ & $73 \pm 0.14$ & $34 \pm 0.07$ & $45 \pm 0.20$ & $90 \pm 0.16$ & $<0.0001 *$ \\
\hline Pack-years (mean \pm SD) & $34.5 \pm 26.8$ & $50 \pm 40$ & $44.6 \pm 36.7$ & - & - \\
\hline $\begin{array}{l}\text { Smoking-free duration (months) } \\
\text { (mean } \pm \text { SD) }\end{array}$ & $226 \pm 151$ & $14 \mid \pm 104$ & $159.6 \pm 122$ & - & - \\
\hline $\mathrm{SpO}_{2}(\%)($ mean $\pm \mathrm{SD})$ & $94 \pm 0.02$ & $87 \pm 0.03$ & $93 \pm 2.4$ & $96 \pm 1$ & $<0.0001 *$ \\
\hline
\end{tabular}

Notes: The data are reported as the mean with the standard deviation and percentage of $\mathrm{SpO}_{2}$. The maximum and minimum age in each group is shown. The spirometry values ( $\mathrm{FEV}_{1} / \mathrm{FVC}$ and $\mathrm{FEV}_{1}$ ) correspond to the values after the use of a bronchodilator. Direct comparison between COPD and healthy controls was performed with Mann-Whitney test, $P<0.05$ was considered significant.

Abbreviations: BMI, body mass index; COPD, chronic obstructive pulmonary disease; FEV , forced expiratory volume in I second; FEV /FVC, ratio of FEV, over FVC; FVC, forced vital capacity; GOLD, Global initiative for chronic Obstructive Lung Disease; SD, standard deviation; SpO ${ }_{2}$, peripheral oxygen saturation. 
than healthy controls (IL-6: $5.42 \pm 3.72 \mathrm{pg} / \mathrm{mL} ; P=0.0188$; IL-8: $13.05 \pm 6.73 \mathrm{pg} / \mathrm{mL} ; P=0.0471$ ) (Figure 1). No differences in serum levels of hs-CRP were observed between COPD patients and controls $(P=0.8827)$ (Figure 1C).

\section{Relationship between serum cytokines and severity parameters}

The intensity of flow obstruction as classified by GOLD, the BODE index criteria (6MWT, BMI, mMRC, and $\mathrm{FEV}_{1}$ ), the number of exacerbations per year, and the post-walking $\mathrm{SpO}_{2}$ test evaluated COPD severity in this study.

The COPD group was GOLD graded, and the IL-6, hsCRP, and IL-8 levels in patients in GOLD stages I-II and stages III-IV were compared to the control group; no differences were observed. Across-group comparison also did not show differences (Table 2).

Table 3 shows the results when the BODE (Figure 2), 6MWT (Figure 2), BMI (Figure 3), mMRC (Figure 3), exacerbation (Figure 4), desaturation (Figure 4), and bronchitis (Figure 5) tests were evaluated. COPD patients that were classified with bronchitis, with more than one exacerbation per year, or with BMI $<21 \mathrm{~kg} / \mathrm{m}^{2}$ presented increased IL-6 levels compared to healthy controls. COPD patients had increased IL-6 levels when did not desaturate or the BODE index $<4$ compared to the controls. The only clinical feature that altered the IL- 8 levels was COPD exacerbation.

\section{Relationship between inflammatory serum biomarkers and the clinical parameters of COPD}

COPD patients with two associated comorbidities exhibited higher IL-6 levels $(34.95 \pm 28.70 \mathrm{pg} / \mathrm{mL} ; P=0.0078)$ than the control group and COPD patients with one associated comorbidity $(6.06 \pm 7.36 \mathrm{pg} / \mathrm{mL} ; P=0.0290)$. The COPD patients with no associated comorbidities exhibited higher
IL-6 levels $(32.97 \pm 31.08 \mathrm{pg} / \mathrm{mL})$ than the control group $(5.42 \pm 3.72 \mathrm{pg} / \mathrm{mL} ; P=0.0110$, Kruskal-Wallis analysis followed by Dunn's test) and COPD patients with one associated comorbidity $(P=0.0124)$.

The IL-8 levels were higher in COPD patients with two comorbidities $(23.63 \pm 14.58 \mathrm{pg} / \mathrm{mL})$ than in the control group (13.05 $\pm 6.73 \mathrm{pg} / \mathrm{mL} ; P=0.0217)$.

COPD patients who smoked between 10 and 30 pack-years exhibited elevated IL-8 levels, but this difference was not significant relative to the control group. IL-6 levels were elevated in COPD patients who smoked more than 30 pack-years $(24.97 \pm 24.91 \mathrm{pg} / \mathrm{mL} ; P=0.0007)$ compared to the control group. IL-8 levels were also elevated in COPD patients who smoked more than 30 pack-years (21.71 $\pm 12.85 \mathrm{pg} / \mathrm{mL} ; P=0.0274)$ compared to the control group. No differences in IL-6 levels between the smoking burden groups were observed.

\section{Discussion}

COPD patients exhibited significantly elevated IL-6 and IL-8 serum levels compared to the control group, which suggests systemic inflammatory activity in stable COPD patients. Higher levels of IL-6 occurred in groups with BMI $<21 \mathrm{~kg} / \mathrm{m}^{2}$, more than two exacerbations in the past year, a higher smoking burden, and bronchitis. Higher levels of IL- 8 were found only in the group with the highest number of exacerbations.

The relationship between interleukins and COPD severity has been more frequently evaluated using the GOLD airflow obstruction classification, but few studies have evaluated the association of interleukins with disease severity on a wider scale. A positive correlation between IL- 6 concentrations and a more rapid decline in $\mathrm{FEV}_{1}$ has been demonstrated previously, but these results were observed in induced sputum. ${ }^{24}$

Serum IL-6 was a better marker, such as the BODE index, $\mathrm{SpO}_{2}$, and the number of exacerbations, which is included
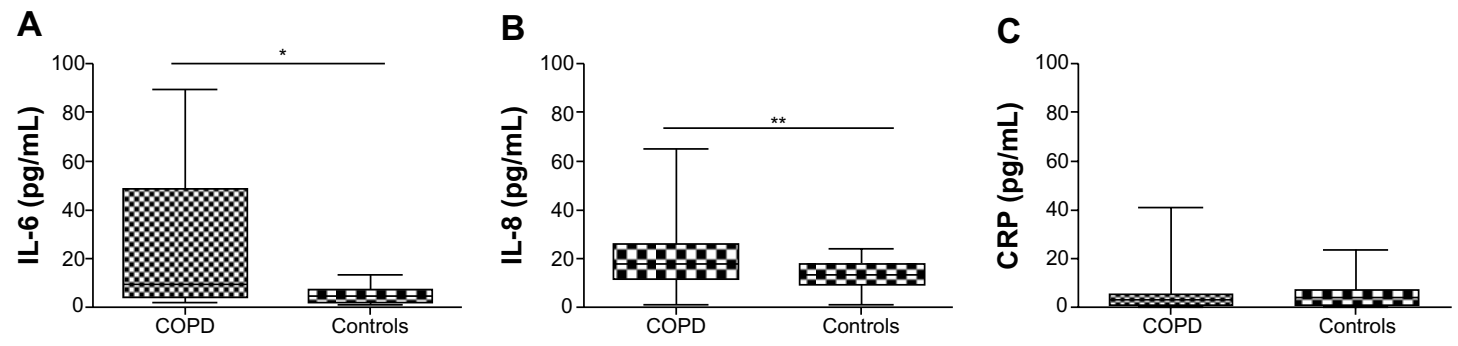

Figure I Cytokine levels $(\mathrm{pg} / \mathrm{mL})$ in individuals with COPD and the control group.

Notes: The results are shown as whiskers boxes; the bars show the median, maximum, and minimum values. (A) IL-6 plasma levels, $* P=0.0$ I 88 ; (B) IL-8 plasma levels, $* * P=0.047 \mathrm{I}$; and $(\mathbf{C})$ serum levels of hs-CRP. $P<0.05$ was considered significant.

Abbreviations: COPD, chronic obstructive pulmonary disease; hs-CRP, highly sensitive C-reactive protein; IL-6, interleukin-6; IL-8, interleukin-8; CRP, C-reactive protein. 
Table 2 Distribution of IL-6 and IL-8 levels in COPD patients in relation to GOLD grading, from November 2010 to October 201 I

\begin{tabular}{lllll}
\hline & Control (16) & GOLD I-II (14) & GOLD III-IV (36) & P-value \\
\hline IL-6 $($ mean \pm SD) & $5.416 \pm 3.72$ & $22.98 \pm 26.68$ & $29.74 \pm 3 \mid .24$ & $0.06 \mid 4$ \\
IL-8 $($ mean \pm SD) & $13.05 \pm 6.73$ I & $20.43 \pm \mid 3.36$ & $21.24 \pm|3.9|$ & 0.01372 \\
CRP $($ mean \pm SD) & $4.815 \pm 5.637$ & $5.542 \pm 8.840$ & $6.378 \pm 9.786$ & 0.08968 \\
\hline
\end{tabular}

Notes: Comparison between the control group and COPD patients grouped by GOLD classification (grades I-II and III-IV). Statistical tests used: the nonparametric Kruskal-Wallis test followed by Dunn's post hoc test. $P<0.05$ was considered significant.

Abbreviations: COPD, chronic obstructive pulmonary disease; GOLD, Global initiative for chronic Obstructive Lung Disease; IL-6, interleukin-6; IL-8, interleukin-8; CRP, C-reactive protein; SD, standard deviation.

in the latest GOLD evaluation (2011). ${ }^{18}$ Celli et a ${ }^{25}$ showed that the association of IL-6 levels with mortality rates was improved when the BODE index and hospital admission history were evaluated. However, the inclusion of other blood biomarkers, as in the current study, did not improve the outcome. IL-6 participates directly in inflammation, and it may be used as a marker of low-grade systemic inflammation and as an additional parameter for risk assessment. ${ }^{25-28}$

The BODE index is currently the most commonly used parameter for the assessment of the risk of death in COPD patients. BMI is a BODE parameter, and it is an important clinical marker of COPD; a low index is translated as a higher mortality risk within this population. ${ }^{29} \mathrm{BMI}$ was lower in COPD patients with more severe GOLD grades in the present study. Systemic inflammatory activity may play a role in weight loss in COPD patients, but no conclusive elements have associated COPD cachexia with the inflammatory process. Approximately $25 \%$ of COPD patients develop cachexia, and the proposed mechanisms include disuse atrophy, energy imbalance, tissue hypoxia, anabolic hormone insufficiency, and systemic inflammation. However, whether the inflammation is the primary cause of cachexia has been impossible to determine until recently. ${ }^{30}$

The walking test is another important clinical marker that is routinely used in COPD patients to assess mortality risk and the capacity to perform daily living activities. Morales et $\mathrm{a}^{31}$ related hs-CRP and IL-6 levels to more exacerbations during the previous year and higher degrees of dyspnea on the 6MWT, but not with the distance walked. In the present study, there was no difference in the concentration of interleukins (IL-6, IL-8) when dividing the groups according to the distance covered.

Dyspnea, as measured by mMRC, is a BODE index parameter that is used to determine COPD severity according to the GOLD criteria (2011)..$^{18}$ Aaron et $a l^{8}$ demonstrated that CRP, IL-6, and IL-8 are significantly associated with worsening dyspnea. However, other studies have only observed this relationship with hs-CRP. ${ }^{9,32}$ The results presented here, however, could not find any association of COPD severity with the three inflammatory biomarkers IL-6, IL-8, and hs-CRP.

A greater number of exacerbations per year may be related to systemic inflammation, and it may indicate

Table 3 Distribution of IL-6 and IL-8 levels in COPD patients in relation to clinical phenotypes

\begin{tabular}{|c|c|c|c|c|}
\hline & IL-6 (mean \pm SD) & $P$-value & IL-8 (mean \pm SD) & $P$-value \\
\hline Control & $5.416 \pm 3.72$ & & $13.05 \pm 6.73$ & \\
\hline Desaturated & $27.78 \pm 5.538^{\#}$ & $0.0566 *$ & $20.3| \pm| 4.1 \mid$ & 0.0927 \\
\hline Did not desaturate & $27.15 \pm 33.25$ & & $22.55 \pm 14.04$ & \\
\hline Bronchitis & $28.88 \pm 31.83^{\#}$ & $0.0468 *$ & $20.46 \pm 4.75$ & 0.0925 \\
\hline Non-bronchitis & $26.31 \pm 28.30$ & & $21.38 \pm 13.07$ & \\
\hline$<$ I exacerbation/year & $22.97 \pm 26.60$ & $0.0439 *$ & $21.08 \pm 11.52^{\#}$ & $0.0288 *$ \\
\hline$>2$ exacerbation/year & $34.92 \pm 33.9 I^{\#}$ & & $21.13 \pm 17.35$ & \\
\hline$\geq 350 \mathrm{~m}$ & $23.93 \pm 28.62$ & 0.0905 & $20.53 \pm 12.76$ & 0.1641 \\
\hline$<350 \mathrm{~m}$ & $23.93 \pm 28.62$ & & $22.23 \pm 17.28$ & \\
\hline BODE $<4$ & $24.94 \pm 28.94$ & $0.0528 *$ & $22.12 \pm|4.8|$ & 0.1285 \\
\hline $\mathrm{BODE} \geq 5$ & $33.44 \pm 30.85$ & & $18.17 \pm 9.866$ & \\
\hline $\mathrm{mMRC}<\mathrm{I}$ & $25.20 \pm 30.63$ & 0.0674 & $23.88 \pm 15.1 I^{\#}$ & $0.0560 *$ \\
\hline $\mathrm{mMRC}>2$ & $28.93 \pm 28.91$ & & $18.91 \pm 11.15$ & \\
\hline $\mathrm{BMI}<2 \mathrm{I}$ & $37.76 \pm 31.04^{\#}$ & $0.0342 *$ & $17.59 \pm 10.09$ & 0.1051 \\
\hline $\mathrm{BMI} \geq 2 \mathrm{I}$ & $20.49 \pm 27.93$ & & $23.26 \pm|5.2|$ & \\
\hline
\end{tabular}

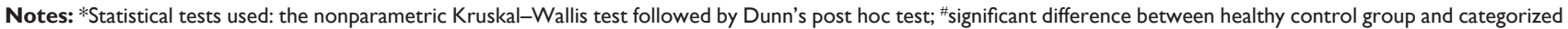
COPD group $(P<0.05)$

Abbreviations: BMI, body mass index; BODE, BMI (body mass index), obstruction, dyspnea, exercise capacity (health index) index; COPD, chronic obstructive pulmonary disease; IL-6, interleukin-6; IL-8, interleukin-8; mMRC, Modified Medical Research Council; SD, standard deviation; m, meters. 


\section{A}

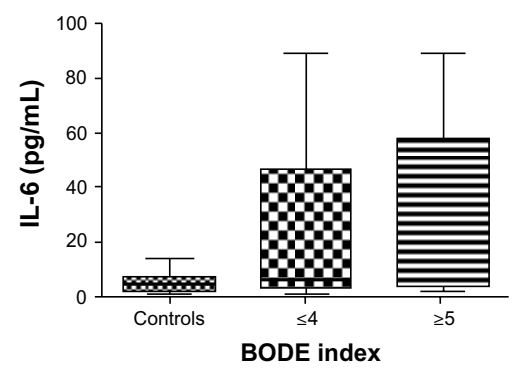

C

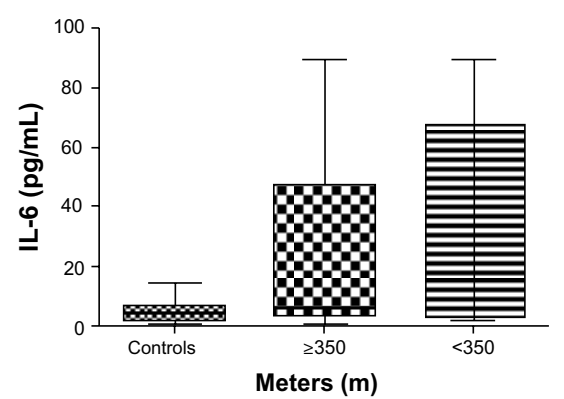

B

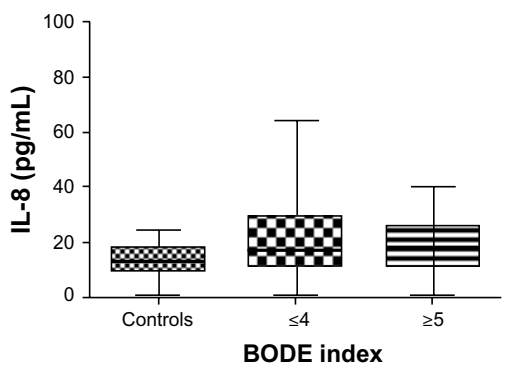

D

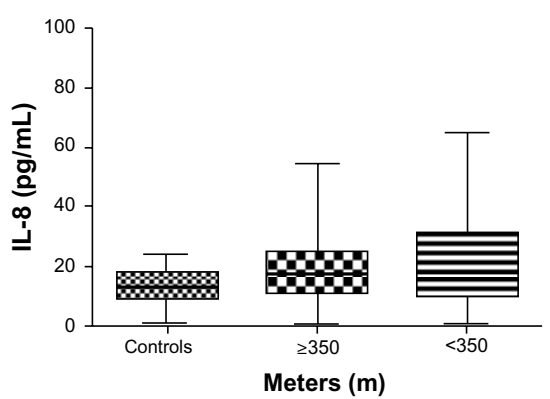

Figure 2 Cytokine levels ( $\mathrm{pg} / \mathrm{mL}$ ) for the control group and COPD patients grouped by BODE index or 6MWT.

Notes: (A) IL-6 plasma levels for the control group and COPD patients with BODE index $<4$ and $\geq 5$. (B) IL-8 plasma levels for the control group and COPD patients with BODE index $<4$ and $\geq 5$. (C) IL-6 plasma levels for the control group and COPD patients who walked $<350 \mathrm{~m}$ and $\geq 350 \mathrm{~m}$ on the $6 \mathrm{MWT}$. (D) IL-8 plasma levels for the control group and COPD patients who walked $<350 \mathrm{~m}$ and $\geq 350 \mathrm{~m}$ on the $6 \mathrm{MWT}$. $P<0.05$ was considered significant.

Abbreviations: 6MWT, 6-minute walking test; BODE, BMI (body mass index), obstruction, dyspnea, exercise capacity (health index) index; COPD, chronic obstructive pulmonary disease; IL-6, interleukin-6; IL-8, interleukin-8.

A

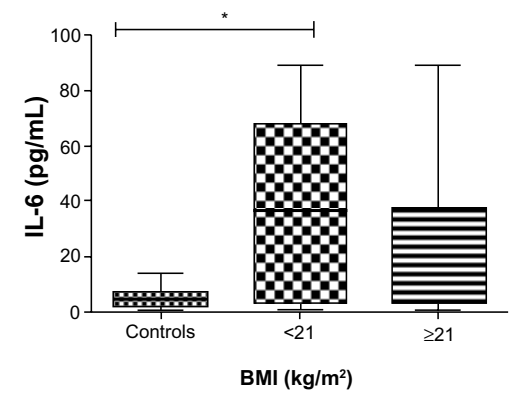

C

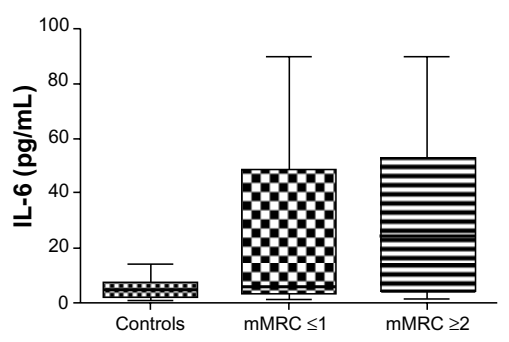

B

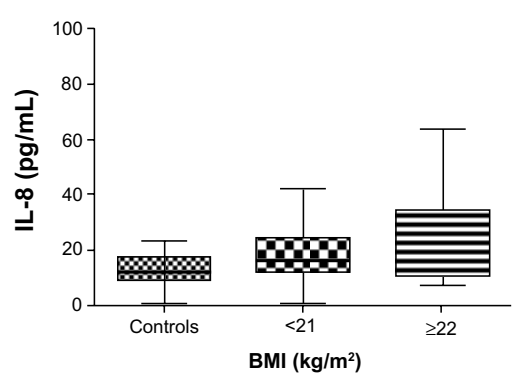

D

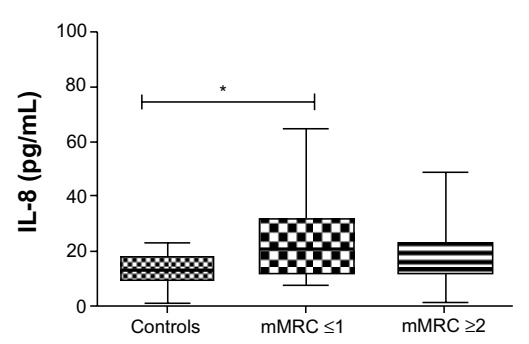

Figure 3 Cytokine levels ( $\mathrm{pg} / \mathrm{mL}$ ) for the control group and COPD patients grouped by BMI and the level of dyspnea measured by mMRC.

Notes: (A) IL-6 plasma levels for the control group and COPD patients with BMI $<21 \mathrm{~kg} / \mathrm{m}^{2}$ and $\geq 2 \mathrm{I} \mathrm{kg} / \mathrm{m}^{2}$. (B) IL-8 plasma levels for the control group and COPD patients with BMI $<2 \mathrm{I} \mathrm{kg} / \mathrm{m}^{2}$ and $\geq 2 \mathrm{I} \mathrm{kg} / \mathrm{m}^{2}$. (C) IL-6 plasma levels for the control group and COPD patients with mMRC $\leq \mathrm{I}$ and $\mathrm{mMRC} \geq 2$ (measuring dyspnea). (D) IL-8 plasma levels for the control group and COPD patients with $\mathrm{mMRC} \leq \mathrm{I}$ and $\mathrm{mMRC} \geq 2$ (measuring dyspnea). $* P<0.05$ was considered significant.

Abbreviations: BMI, body mass index; COPD, chronic obstructive pulmonary disease; IL-6, interleukin-6; IL-8, interleukin-8; mMRC, Modified Medical Research Council. 
A

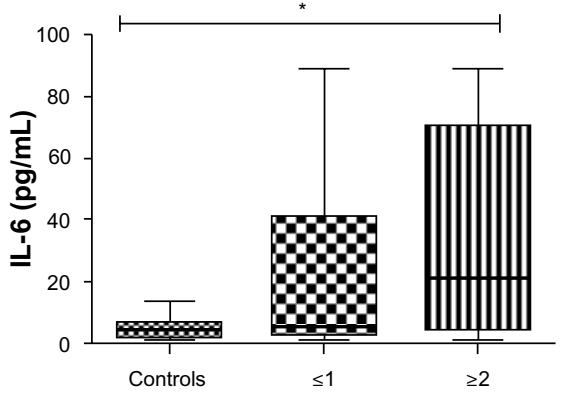

C

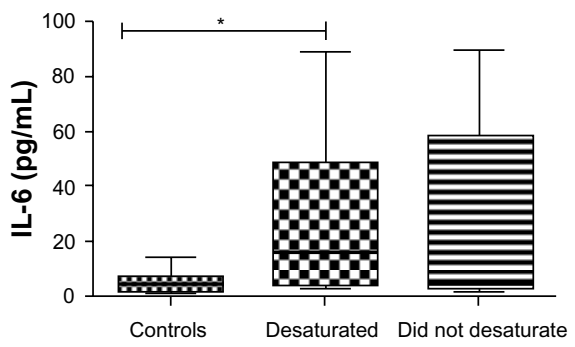

B

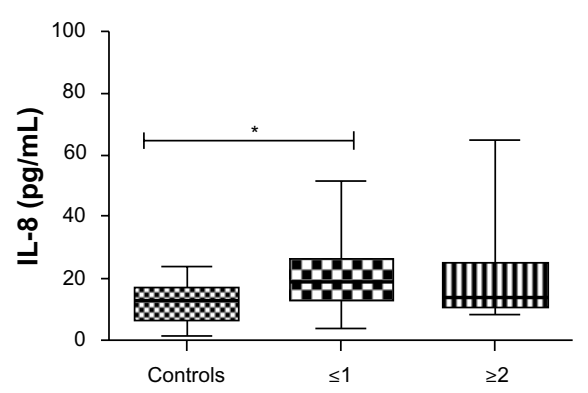

D

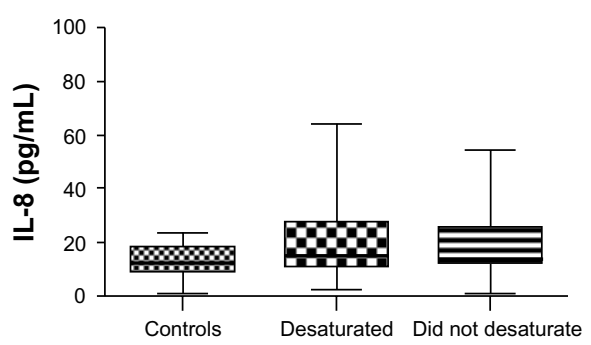

Figure 4 Cytokine levels $(\mathrm{pg} / \mathrm{mL})$ for the control group and COPD patients grouped by number of exacerbations per year and whether or not they desaturated after the walking test.

Notes: (A) IL-6 plasma levels for the control group and COPD patients with $\leq \mathrm{I}$ and $\geq 2$ exacerbations per year. (B) IL-8 plasma levels for the control group and COPD patients with $\leq \mathrm{I}$ and $\geq 2$ exacerbations per year. (C) IL-6 plasma levels for the control group and COPD patients who did and did not desaturate after the walking test. (D) IL-8 plasma levels for the control group and COPD patients who did and did not desaturate after the walking test. $* P<0.05$ was considered significant.

Abbreviations: COPD, chronic obstructive pulmonary disease; IL-6, interleukin-6; IL-8, interleukin-8.

increased inflammatory activity in these patients, which can persist after recovery. Higher levels of IL-6 were exhibited in individuals with at least one exacerbation per year in the present study. Patients with more than 2.5 exacerbations per year exhibited an increase in IL-6 that was related to a more rapid loss of $\mathrm{FEV}_{1} \cdot{ }^{24}$ These exacerbations are important in COPD progression, but this disease's mechanisms are not fully understood.

The levels of IL-8 were elevated in COPD patients who smoked more than 30 pack-years. Smoking burden may also be associated with systemic inflammatory activity. It may be that IL-8 is a good biomarker only for ex-smokers. Patients with the same degree of obstruction but different clinical phenotypes may exhibit differences in local or systemic inflammation. ${ }^{33}$

Individuals who smoked a higher number of cigarettes exhibited higher concentrations of IL-6 and IL-8; additionally, it has been suggested that systemic inflammatory reactions persist after smoking cessation. Previous studies have been performed on individuals who maintained their smoking habit
A

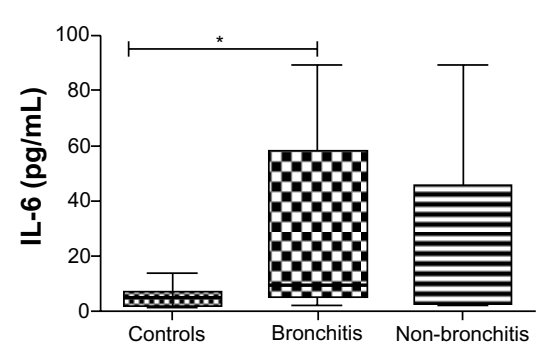

B

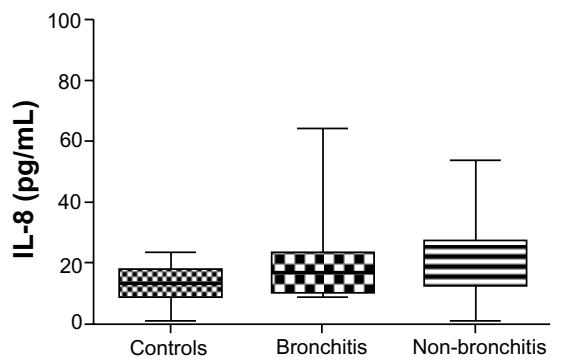

Figure 5 Cytokine levels $(\mathrm{pg} / \mathrm{mL})$ for the control group and COPD patients grouped as with or without bronchitis.

Notes: (A) IL-6 plasma levels for the control group and COPD patients with and without bronchitis. (B) IL-8 plasma levels for the control group and COPD patients with and without bronchitis. $* P<0.05$ was considered significant.

Abbreviations: COPD, chronic obstructive pulmonary disease; IL-6, interleukin-6; IL-8, interleukin-8. 
and a greater release of IL- 8 is observed in these patients, which increases the number of neutrophils and lymphocytes in the sputum. ${ }^{34}$ IL-8 was more elevated in individuals with COPD than in smokers without flow obstruction. ${ }^{35}$

The number of comorbidities was not clearly associated with systemic inflammation in the present study, probably because individuals who were using statins were also excluded, since these drugs may exert anti-inflammatory activity. Watz et $\mathrm{al}^{36}$ reported that an average of $47.7 \%$ of COPD patients exhibited metabolic syndrome. They also demonstrated significantly elevated hs-CRP and IL-6 in patients with metabolic syndrome and physical inactivity independent of pulmonary function.

The presence of comorbidities may be a confounding factor because many comorbidities also induce systemic inflammation. ${ }^{37,38}$ However, the mechanisms underlying the association of COPD with comorbidities are not fully understood. ${ }^{39}$ No significant differences in the incidence and type of comorbidity were observed between the control and study groups, except for the higher incidence of arterial hypertension in the control group. However, these individuals were selected from an arterial hypertension clinic.

The present study has several limitations, such as the crosssectional design, the sample size, and the evaluation of only a small number of biomarkers. The identification of disease biomarkers may be important for the diagnostics and prognostics of COPD and may provide better guidance for treatment. However, longitudinal studies are required to evaluate the longterm behavior of inflammatory biomarkers in COPD.

In conclusion, smoking cessation does not decrease IL-6 levels since increased IL-6 was mainly associated with smoking burden in COPD patients who had smoked for more than 30 pack-years and exhibited a bronchitis phenotype. No direct association was observed for both IL-6 and IL-8 blood levels with the severity of COPD in ex-smokers.

\section{Acknowledgments}

The authors are thankful to Maria Barbosa Alves, Maria Auxiliadora Carmo Moreira, and Jozelia Rêgo for critically revising the study.

The authors also thank José Laerte Rodrigues da Silva Junior for the statistical analysis.

\section{Disclosure}

The authors report no conflicts of interest in this work.

\section{References}

1. Mannino DM. COPD: epidemiology, prevalence, morbidity and mortality, and disease heterogeneity. Chest. 2002;121(Suppl 5):121S-126S.
2. Pauwels RA, Rabe KF. Burden and clinical features of chronic obstructive pulmonary disease (COPD). Lancet. 2004;364(9434):613-620.

3. Cosio MG, Saetta M,Agusti A. Immunologic aspects of chronic obstructive pulmonary disease. N Engl J Med. 2009;360(23):2445-2454.

4. Fabbri LM, Romagnoli M, Corbetta L, et al. Differences in airway inflammation in patients with fixed airflow obstruction due to asthma or chronic obstructive pulmonary disease. Am J Respir Crit Care Med. 2003;167(3):418-424.

5. Hogg JC. Pathophysiology of airflow limitation in chronic obstructive pulmonary disease. Lancet. 2004;364(9435):709-721.

6. Saetta M, Di Stefano A, Turato G, et al. CD8+ T-lymphocytes in peripheral airways of smokers with chronic obstructive pulmonary disease. Am J Respir Crit Care Med. 1998;157(3 Pt 1):822-826.

7. Barnes PJ, Celli BR. Systemic manifestations and comorbidities of COPD. Eur Respir J. 2009;33(5):1165-1185.

8. Aaron SD, Vandemheen KL, Ramsay T, et al. Multi analyte profiling and variability of inflammatory markers in blood and induced sputum in patients with stable COPD. Respir Res. 2010;11:41.

9. Garcia-Rio F, Miravitlles M, Soriano JB, et al; EPI-SCAN Steering Committee. Systemic inflammation in chronic obstructive pulmonary disease: a population-based study. Respir Res. 2010;11:63.

10. Piehl-Aulin K, Jones I, Lindvall B, Magnuson A, Abdel-Halim SM. Increased serum inflammatory markers in the absence of clinical and skeletal muscle inflammation in patients with chronic obstructive pulmonary disease. Respiration. 2009;78(2):191-196.

11. He Z, Chen Y, Chen P, Wu G, Cai S. Local inflammation occurs before systemic inflammation in patients with COPD. Respirology. 2010;15(3): 478-484.

12. Ferrari R, Tanni SE, Caram LM, Corrêa C, Corrêa CR, Godoy I. Three-year follow-up of Interleukin 6 and C-reactive protein in chronic obstructive pulmonary disease. Respir Res. 2013;14:24.

13. Garcia-Aymerich J, Gómez FP, Benet M, et al; PAC-COPD Study Group. Identification and prospective validation of clinically relevant chronic obstructive pulmonary disease (COPD) subtypes. Thorax. 2011;66(5):430-437.

14. Agustí A, Edwards LD, Rennard SI, et al; Evaluation of COPD Longitudinally to Identify Predictive Surrogate Endpoints (ECLIPSE) Investigators. Persistent systemic inflammation is associated with poor clinical outcomes in COPD: a novel phenotype. PLoS One. 2012;7(5):e37483.

15. Yao H, Rahman I. Current concepts on oxidative/carbonyl stress, inflammation and epigenetics in pathogenesis of chronic obstructive pulmonary disease. Toxicol Appl Pharmacol. 2011;254(2):72-85.

16. Liu J, Liang Q, Frost-Pineda K, et al. Relationship between biomarkers of cigarette smoke exposure and biomarkers of inflammation, oxidative stress, and platelet activation in adult cigarette smokers. Cancer Epidemiol Biomarkers Prev. 2011;20(8):1760-1769.

17. Willemse BW, ten Hacken NH, Rutgers B, Postma DS, Timens W. Association of current smoking with airway inflammation in chronic obstructive pulmonary disease and asymptomatic smokers. Respir Res. 2005;6:38.

18. Global Initiative for Chronic Obstructive Lung Disease. Global Strategy for the Diagnosis, Management and Prevention of COPD: GOLD Revised 2011. Available from: http://www.goldcopd.org/uploads/users/ files/GOLD_Report_2011_Jan21.pdf. Accessed May 20, 2011.

19. Ciba Foundation Guest Symposium. Terminology, definition and classification of chronic pulmonary emphysema and related conditions. Thorax. 1959;14(4):286-299.

20. Menezes AM. Epidemiologia da bronquite crônica e do enfisema (DPOC): até onde sabemos? [Bronchitis and emphysema epidemiology: what do we know?] J Pneumol. 1997;23(3):153-157. Portugese.

21. Miller MR, Hankinson J, Brusasco V, et al; ATS/ERS Task Force. Standardisation of spirometry. Eur Respir J. 2005;26(2):319-338.

22. Pereira CA, Sato T, Rodrigues SC. New reference values for forced spirometry in white adults in Brazil. J Bras Pneumol. 2007;33(4): 397-406.

23. ATS Committee on Proficiency Standards for Clinical Pulmonary Function Laboratories. ATS statement: guidelines for the six-minute walk test. Am J Respir Crit Care Med. 2002;166(1):111-117. 
24. Donaldson GC, Seemungal TAR, Patel IS, et al. Airway and systemic inflammation and decline in lung function in patients with COPD. Chest. 2005;128(4):1995-2004.

25. Celli BR, Locantore N, Yates J, et al; ECLIPSE Investigators. Inflammatory biomarkers improve clinical prediction of mortality in chronic obstructive pulmonary disease. Am J Respir Crit Care Med. 2012;185(10):1065-1072.

26. Pinto-Plata V, Casanova $\mathrm{C}$, Mullerova $\mathrm{H}$, et al. Inflammatory and repair serum biomarker pattern. Association to clinical outcomes in COPD. Respir Res. 2012;13:71.

27. Eickhoff P, Valipour A, Kiss D, et al. Determinants of systemic vascular function in patients with stable chronic obstructive pulmonary disease. Am J Respir Crit Care Med. 2008;178(12):1211-1218.

28. Breyer MK, Rutten EP, Vernooy JH, et al. Gender differences in the adipose secretome system in chronic obstructive pulmonary disease (COPD): a pivotal role of leptin. Respir Med. 2011;105(7):1046-1053.

29. Celli BR, Cote CG, Marin JM, et al. The body-mass index, airflow obstruction, dyspnea, and exercise capacity index in chronic obstructive pulmonary disease. N Engl J Med. 2004;350(10):1005-1012.

30. Wagner PD. Possible mechanisms underlying the development of cachexia in COPD. Eur Respir J. 2008;31(3):492-501.

31. Morales SA, Dreyse DJ, Díaz PO, Saldías PF, Carrasco M, Lisboa BC. [Systemic inflammation among stable ex smokers with chronic obstructive pulmonary disease]. Rev Med Chil. 2010;138(8):957-964 Spanish.

32. de Torres JP, Pinto-Plata V, Casanova C, et al. C-reactive protein levels and survival in patients with moderate to very severe COPD. Chest. 2008;133(6):1336-1343.
33. Izquierdo JL, Almonacid C, Parra T, Pérez J. [Systemic and lung inflammation in 2 phenotypes of chronic obstructive pulmonary disease]. Arch Bronconeumol. 2006;42(7):332-337. Spanish.

34. Van der Vaart H, Postma DS, Timens W, et al. Acute effects of cigarette smoking on inflammation in healthy intermittent smokers. Respir Res. 2005;6:22.

35. Willemse BW, ten Hacken NH, Rutgers B, Postma DS, Timens W. Association of current smoking with airway inflammation in chronic obstructive pulmonary disease and asymptomatic smokers. Respir Res. 2005;6:38.

36. Watz H, Waschki B, Kirsten A, et al. The metabolic syndrome in patients with chronic bronchitis and COPD: frequency and associated consequences for systemic inflammation and physical inactivity. Chest. 2009;136(4):1039-1046.

37. Thomsen M, Dahl M, Lange P, Vestbo J, Nordestgaard BG. Inflammatory biomarkers and comorbidities in chronic obstructive pulmonary disease. Am J Respir Crit Care Med. 2012;186(10): 982-988.

38. Divo M, Cote C, de Torres JP, et al; BODE Collaborative Group. Comorbidities and risk of mortality in patients with chronic obstructive pulmonary disease. Am J Respir Crit Care Med. 2012;186(2): $155-161$.

39. Sin DD, Man SF. Why are patients with chronic obstructive pulmonary disease at increased risk of cardiovascular diseases? The potential role of systemic inflammation in chronic obstructive pulmonary disease. Circulation. 2003;107(11):1514-1519.
International Journal of COPD

\section{Publish your work in this journal}

The International Journal of COPD is an international, peer-reviewed journal of therapeutics and pharmacology focusing on concise rapid reporting of clinical studies and reviews in COPD. Special focus is given to the pathophysiological processes underlying the disease, intervention programs, patient focused education, and self management protocols.

\section{Dovepress}

This journal is indexed on PubMed Central, MedLine and CAS. The manuscript management system is completely online and includes a very quick and fair peer-review system, which is all easy to use. Visit http://www.dovepress.com/testimonials.php to read real quotes from published authors. 